BMJ Open

Diabetes

Research

\& Care

\title{
Mining treatment patterns of glucose- lowering medications for type 2 diabetes in the Netherlands
}

\author{
Jan Maurik van den Heuvel (D) , ${ }^{1}$ Niloufar Farzan, ${ }^{1}$ Mandy van Hoek (D) , \\ Anke-Hilse Maitland-van der Zee, ${ }^{1}$ Fariba Ahmadizar ${ }^{3}$
}

To cite: van den Heuvel JM, Farzan N, van Hoek M, et al. Mining treatment patterns of glucose-lowering medications for type 2 diabetes in the Netherlands. BMJ Open Diab Res Care 2020;8:e000767. doi:10.1136/ bmjdrc-2019-000767

- Additional material is published online only. To view please visit the journal online (http://dx.doi.org/10.1136/ bmjdrc-2019-000767).

The abstract of this article was presented at the International Conference for Pharmacoepidemiology (ICPE) in Prague, in August 2018.

Received 18 July 2019 Revised 12 November 2019 Accepted 26 November 2019

Check for updates

C Author(s) (or their employer(s)) 2020. Re-use permitted under CC BY-NC. No commercial re-use. See rights and permissions. Published by BMJ.

For numbered affiliations see end of article.

Correspondence to Dr Jan Maurik van den Heuvel; maurik.vandenheuvel@ breathomix.com

Dr Fariba Ahmadizar; f.ahmadizar@erasmusmc.nl

\section{ABSTRACT}

Rationale and objectives Different classes of glucoselowering medications are used for patients with type 2 diabetes mellitus (T2DM) management. It is unclear how often these medications are prescribed in clinical practice. In this study, we aimed to describe treatment patterns of glucose-lowering medications in patients with T2DM in the Netherlands.

Methods We studied a cohort of 73819 patients with T2DM, aged $\geq 45$ years with a first prescription for oral glucose-lowering medication between 2011 and 2017. We used the NControl database with dispensing data from 800 pharmacies in the Netherlands. Prevalence of each glucose-lowering medication class during 6 years after the index date was calculated. Using SQL Server, we identified stepwise patterns of medication prescription in this population.

Findings During the study period, prevalence of biguanides (BIGU) decreased from $95.6 \%$ to $80.8 \%$ and use of sulfonylureas (SU) increased from $27.3 \%$ to $42.3 \%$. $55.2 \%$ of all patients only received BIGUs, $19.1 \%$ of all patients started on BIGUs but switched to BIGU +SU. $13.5 \%$ of patients with T2DM initiated insulins, on average 532 days (almost 18 months) after the index date.

Conclusions Our findings showed that in the Netherlands, medication treatment in patients with T2DM is mainly consistent with the clinical guidelines in the Netherlands during the study period.

\section{INTRODUCTION}

Type 2 diabetes mellitus (T2DM) is one of the most common chronic disorders, with a worldwide estimated prevalence of $9 \%$ in 2014. ${ }^{1}$ According to the International Diabetes Federation, among the adult (age 20-79 years) population of 661 million in Europe in 2017, the prevalence of T2DM has been estimated at $6.9 \%$ (ranging between $5.5 \%$ and $9.9 \%) .^{2}$ In the Netherlands, in 2013, this percentage was $5.5 \%$ (measured among a study population of 8 million inhabitants; roughly half of the total population). ${ }^{3}$ T2DM has been related to increased risk of comorbidities, for example, cardiovascular disease, with 5 million deaths annually. ${ }^{1}$

\section{Significance of this study}

What is already known about this subject?

- Despite the global dissemination of recommendations from the available guidelines, current clinical practice patterns for patients who initiate glucoselowering agents is not well known. The process by which physicians in the Netherlands choose glucose-lowering medications to treat patients with T2DM is poorly understood.

What are the new findings?

- Our findings showed that in the Netherlands, medication treatment in patients with T2DM is mainly consistent with the clinical guidelines in the Netherlands during the study period.

How might these results change the focus of research or clinical practice?

- Identifying factors associated with switching would help guide clinicians toward a medication treatment choice and could also help patients to improve their response to treatment.

Different classes of glucose-lowering medications with different efficacy, side effects and tolerability have been approved for T2DM management. ${ }^{4}$ According to the Dutch clinical guidelines and the American Diabetes Association (ADA), until 2018 and during the study period, a medication treatment algorithm in T2DM based on diabetes progression was used. Treatment begins with biguanides (BIGUs) such as metformin, adds a sulfonylurea (SU) when BIGUs do not adequately control hyperglycemia, then adds basal insulins, and eventually moves on to more intensive pharmacotherapy with insulins. ${ }^{5-7}$

Despite the global dissemination of recommendations from the available guidelines, current clinical practice patterns for patients who initiate glucose-lowering agents is not well known. The process by which physicians in the Netherlands choose glucose-lowering 
medications to treat patients with T2DM is poorly understood.

We, therefore, among a population with T2DM in the Netherlands aimed to investigate the prevalence of glucose-lowering medications dispensed by community pharmacies, and to show the most frequent sequential patterns in the treatment of T2DM, during 6 years after the onset of diabetes. We further assessed if age or gender affected treatment patterns.

\section{METHODS}

Research design and study setting

In a longitudinal retrospective follow-up study, we used data obtained between 2012 and 2017 from the NControl database that includes dispensing data from 800 pharmacies (approximately 6 million patients) located in different regions of the Netherlands. This database has been a source for multiple studies ${ }^{89}$ and includes information on patient demographics (age and gender) and drug dispensing records from mainly community pharmacies and, to a lesser extent, outpatient pharmacies located in the hospitals. Detailed information on the dispensed drug, type of prescriber, dispensing dates, the amount dispensed, and the written dose instructions are also available in this database.

\section{Glucose-lowering medications use}

As shown in online supplementary table S1, glucoselowering medications were coded according to the Anatomical Therapeutic Chemical (ATC) codes: A10A (insulin preparations) and $\mathrm{A} 10 \mathrm{~B}$ (oral glucose-lowering medication) ${ }^{10}$ Exposure to glucose-lowering medications was defined as a dispensing record of a prescription for the medications categorized into the following groups (ATC code between brackets): (1) BIGUs (A10BA); (2) SU (A10BB); (3) alpha-glucosidase inhibitors (A10BF); (4) thiazolidinediones (A10BG); (5) dipeptidyl peptidase 4 (DPP-4) inhibitors (A10BH); (6) glucagon-like peptide-1 (GLP-1) analogues (A10BJ); (7) sodium-glucose co-transporter 2 (SGLT2) inhibitors (A10BK); and (8) insulins (A10A) (online supplementary table S1).

\section{Defining treatments, switches and add-ons}

We define treatments based on the medication that the patient has in his possession at any given point in time. We use the daily defined dose as defined by the WHO to calculate the number of days for which any of the above groups of medication is dispensed. ${ }^{10}$ We report a switch when the medication group in the patients possession changes from one group to one or more other groups. We report an add-on if a new group of medication is dispensed, while the previously dispensed medication is still in the patient's possession. We add a buffer of 30 days to each dispension to correct for medication possession gaps that may occur due to non-adherence. This has the additional wanted effect that a treatment that is made up from multiple medications that are dispensed asynchronously, but shortly after each other, will be reported as one unchanged treatment, rather than many recurring switches back and forth between the same medications.

\section{Study population}

All patients who filled at least two oral glucose-lowering medication prescriptions (A10B) during the follow-up (from 2012 to 2017) were considered to have T2DM. The date of first ever oral glucose-lowering medication dispensing was selected as the cohort entry date (index date). Patients were eligible for inclusion in the study if they had at least 12-month follow-up, calculated as the number of days between their first and last prescription of diabetes medication. We only included patients that were newly diagnosed during our study period. These are patients that received no diabetes medication during the 12 months before the index date. Two approaches were used to minimize the risk of possible type 1 diabetes misclassification: individuals who were initially treated with insulin as monotherapy were excluded, and only patients aged 45 years and older at which age the risk of developing T2DM increases were selected. ${ }^{11}{ }^{12}$

\section{Statistical analysis}

Descriptive statistics were used to summarize the characteristics of patients with T2DM. Overall and annual prevalence of each class of glucose-lowering medications were calculated in the period 6 years after the index date. Characteristics of patients who were treated with insulins during follow-up were further studied as well. We used a $\chi^{2}$ statistical test to test if the differences between different age groups (45-55, 56-65 and $\geq 66$ years) and gender were statistically significant.

Using SQL Server Management Studio, treatment steps were studied. We report overviews of the most frequent two-step combinations. A two-step combination is a change from one treatment to another. (In our analysis, Start and End of observation are considered treatment steps.) In subgroup analyses, treatment steps were compared between genders.

\section{Data availability}

The data that support the findings of this study are available from NControl B.V. but restrictions apply to the availability of these data, which are not publicly available. Data are, however, available from the authors on reasonable request and with permission of NControl B.V.

\section{Resource availlability}

No applicable resources were generated or analyzed during the current study.

\section{RESULTS}

\section{Baseline characteristics}

A total of 73819 eligible patients with T2DM aged $\geq 45$ years at the index date were identified (table 1). The mean age at the index date was $65.0 \pm 11.2$ years and the majority of patients included in this study were men $(54.9 \%)$. At the index date, $46.8 \%$ of patients were aged 
Table 1 Baseline characteristics of patients with T2DM, and patients who received insulin

\begin{tabular}{|c|c|c|c|}
\hline & & $\begin{array}{l}\text { T2DM cohort } \\
(\mathrm{n}=73819)\end{array}$ & $\begin{array}{l}\text { Patients with } \\
\text { T2DM with } \\
\text { insulin during } \\
\text { follow-up } \\
\text { (n=9969) }\end{array}$ \\
\hline \multirow{3}{*}{$\begin{array}{l}\text { Gender, } \\
\text { n (\%) }\end{array}$} & Male & 40521 (54.9) & 5277 (52.9) \\
\hline & Female & 33298 (45.1) & $4692(47.1)$ \\
\hline & & $\begin{array}{l}\text { Age at first } \\
\text { glucose-lowering } \\
\text { medication use } \\
\text { (index date) }\end{array}$ & $\begin{array}{l}\text { Age at first } \\
\text { insulin use }\end{array}$ \\
\hline \multirow{3}{*}{$\begin{array}{l}\text { Age, } \\
\text { n (\%) }\end{array}$} & $45-55$ y & 17444 (23.6) & $2640(26.5)$ \\
\hline & $56-65$ y & 21816 (29.6) & $2800(28.1)$ \\
\hline & $\geq 66$ y & $34559(46.8)$ & $4529(45.4)$ \\
\hline
\end{tabular}

T2DM, type 2 diabetes mellitus.

$\geq 66$ years. The average follow-up period for all patients was 1188 days, calculated as the number of days between their first and last diabetes prescription.

As shown in figure 1, the overall prevalence of BIGUs and SUs were $96.3 \%$ and $41.7 \%$, respectively. Most patients start on BIGU, but during the follow-up, there was a slight decrease in the use of BIGUs (from $95.6 \%$ to $80.8 \%$ ). At the same time, an increase in the use of SUs and DPP-4 inhibitors was observed, from $27.3 \%$ to $42.3 \%$ and from $3.7 \%$ to $7.9 \%$, respectively (figure 1). Overall, the prevalence of SGLT2 inhibitors (1.3\%) and GLP-1 analogues $(1.2 \%)$ was low, but they showed an increase in the use during the 6 years after index date in this population. No significant differences in the prevalence of oral glucose-lowering medications were seen between patients in different age groups and gender.

A total of $9969(13.5 \%)$ patients with T2DM used insulin at some point during follow-up. Patients in the age group of 45-55 years at the index date were more likely to initiate treatment with insulin during follow-up $(\mathrm{p}<0.001)$. Most of the patients who used insulin were men $(52.9 \%$ men vs $47.1 \%$ women, even though women only represent $45.1 \%$ of the study population; $\mathrm{p}$ value $<0.001$ ) (table 1 ). The average time of switching to insulin therapy in this population was roughly 18 months after the index date.

Figure 2 shows the most frequently observed treatment steps for each drug class during the follow-up. The majority of patients with T2DM (55.2\%) only received BIGUs and $19.1 \%$ of all patients started BIGUs and then added SU (treatment BIGU+SU). Switching from BIGU to SU happened in $8.2 \%$ of this population (figure 2). In $23.8 \%$ of all patients, the last measured treatment during follow-up was BIGU+SU. According to the standards, this treatment is the first step after BIGU, meaning that patients have not progressed further in the treatment path, at least not during our study period. In a small percentage of patients, the last measured treatment during the follow-up consisted of insulins $(0.8 \%)$ as monotherapy, insulins combined with BIGUs $(4.6 \%)$, or insulins with BIGU+SU (4.9\%).

The most important different treatment paths are shown in figure 2 . The average time interval between

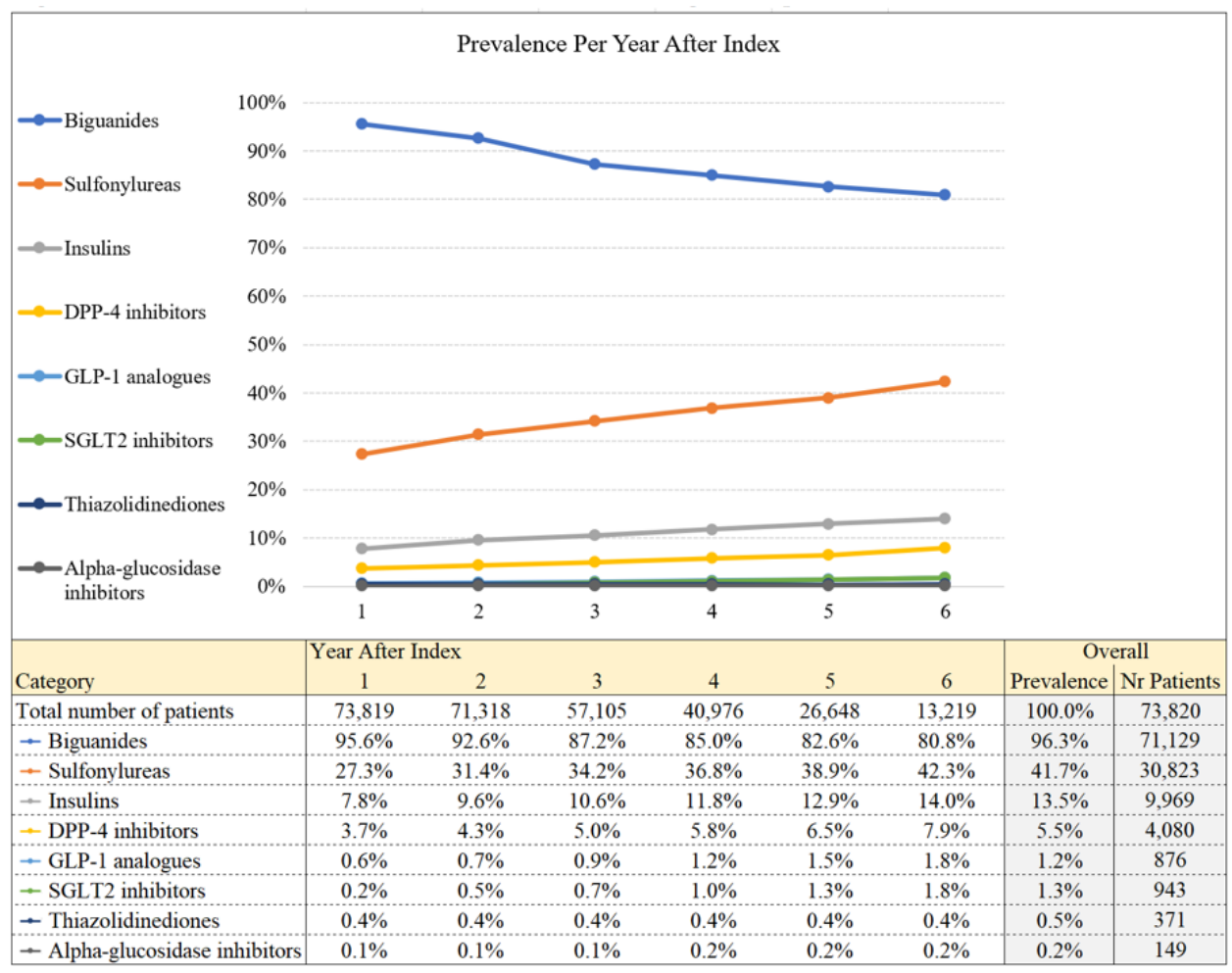

Figure 1 Prevalence of different classes of diabetes medications during follow-up. 


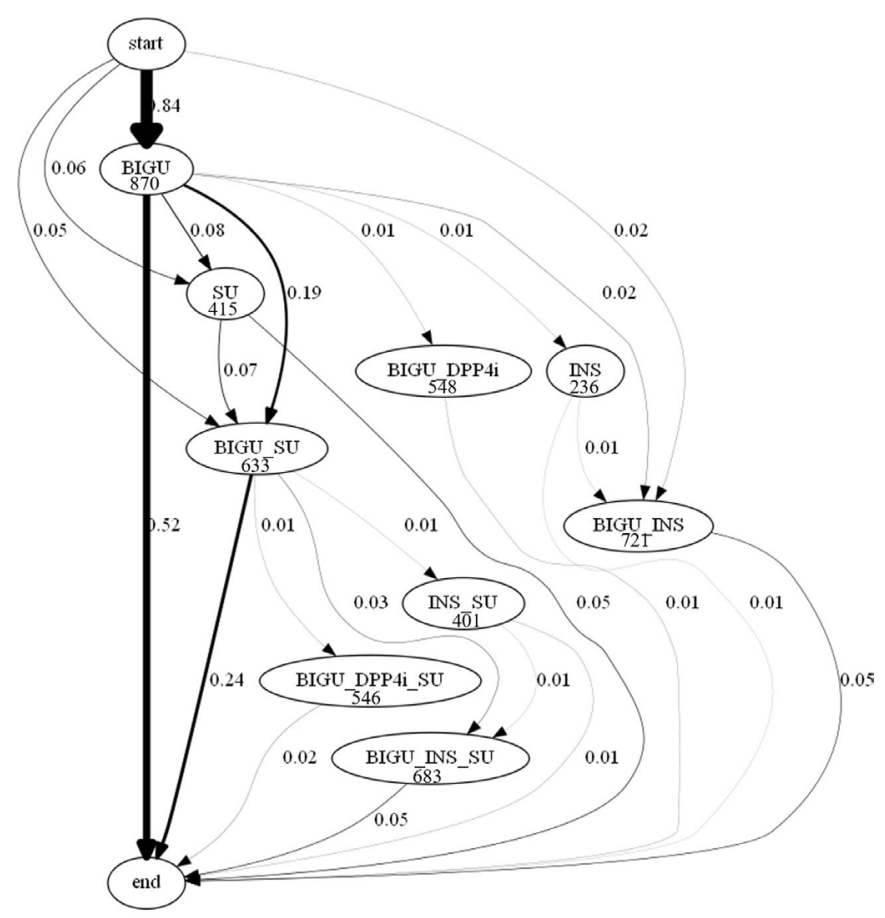

Figure 2 T2DM treatment paths, all patients. Numbers next to the arrows represent the percentage of patients taking the represented step in the treatment path. Numbers below treatments represent the average number of days on this treatment. T2DM, type 2 diabetes mellitus.

switching from mono therapy with BIGUs to combination therapy was roughly 14 months after the index date. Figure $3 \mathrm{~A}, \mathrm{~B}$ shows the treatment paths separately in men and women, with no clinically significant differences. We do find that the switch to or add-on of insulin takes place relatively quickly compared with other medication classes. This happens across age categories and genders (table 2).

\section{DISCUSSION}

To the best of our knowledge, this study is the first largescale study ( $\mathrm{n}=73819$ patients with T2DM) to investigate treatment patterns in patients with diabetes in the Netherlands. Over the study period, most patients received BIGUs $(96.3 \%)$ followed by SUs $(41.7 \%)$. Only a very small proportion of patients with T2DM used SGLT2 inhibitors $(1.3 \%)$ and GLP-1 analogues $(1.2 \%)$ over the study period. In a total of $13.5 \%$ of this population, insulins were initiated and added to other glucose-lowering medications, which may represent progression to a more severe form of T2DM where insulin is indicated.

According to the Netherlands standard for General Practitioners, by the Nederlands Huisartsen Genootschap (Netherlands General Practitioners Society) (NHG) and the consensus statement from the ADA and the European Association for the Study of Diabetes, BIGUs such as metformin are recommended as initial therapy in patients with T2DM. ${ }^{5-7}$ Intensive treatment with metformin appeared to reduce the risk of diabetesassociated complications and all-cause mortality. ${ }^{13}$ Furthermore, according to the results of the UK Prospective Diabetes Study, metformin is recommended as the first-line therapy in patients with T2DM. ${ }^{13}$ In line with most previous studies and according to the guidelines in the Netherlands and ADA recommendations, our study showed that medication treatment was initiated with metformin in $95.6 \%$ of patients with T2DM. ${ }^{6}{ }^{14}$ One exception is a study performed by Berkowitz et al, in the USA, which reported that only $57.8 \%$ of patients with
A

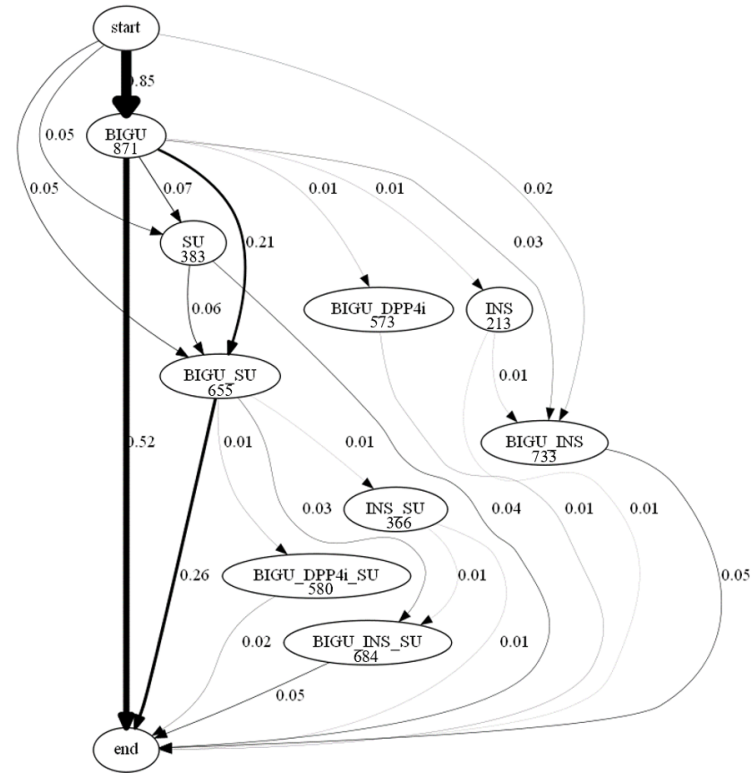

B

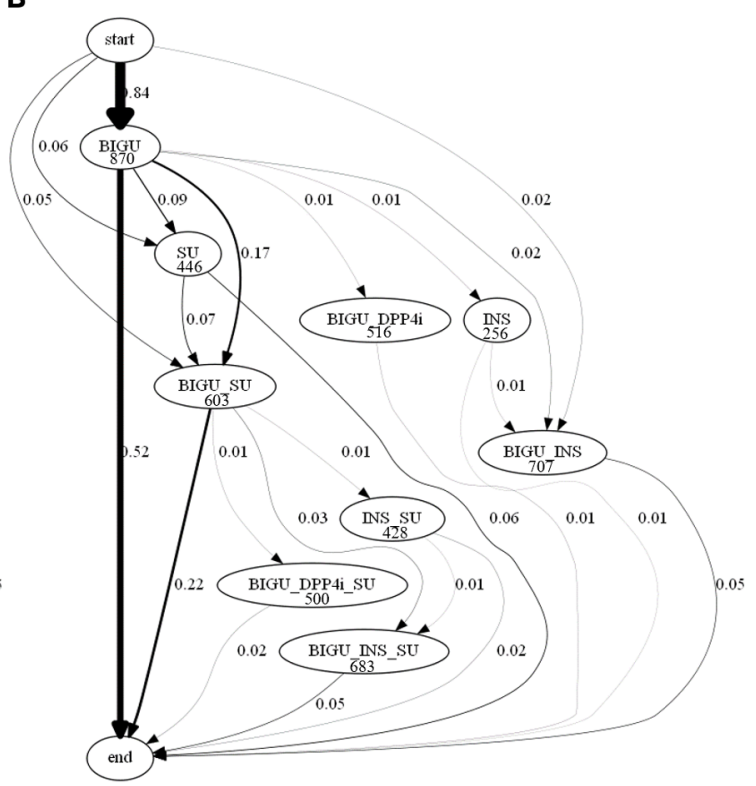

Figure 3 T2DM treatment paths by gender. Numbers next to the arrows represent the percentage of patients taking the represented step in the treatment path. Numbers below treatments represent the average number of days on this treatment. T2DM, type 2 diabetes mellitus. 
Table 2 Average days on biguanides before changing treatment

\begin{tabular}{lllllll}
\hline Switch to & All patients & Males & Females & 45-55 & $\mathbf{5 6 - 6 5}$ & $\mathbf{6 6 +}$ \\
\hline BIGU+DPP-4-i & 364 & 365 & 361 & 357 & 384 & 349 \\
BIGU+INS & 203 & 192 & 218 & 183 & 188 \\
BIGU+SU & 481 & 486 & 474 & 488 & 503 & 452 \\
INS & 248 & 274 & 222 & 224 & 225 \\
SU & 412 & 438 & 387 & 428 & 444 & 384 \\
\hline
\end{tabular}

BIGU, biguanides; DPP, dipeptidyl peptidase; INS, insulin; SU, sulfonylurea.

T2DM started treatment with metformin. Interestingly, in the study by Berkowitz et al, researchers found that initial use of metformin was associated with a lower risk of subsequent treatment intensification compared with the other oral glucose-lowering medications. ${ }^{15}$ In our study, the high percentage of metformin selected as the firstline medication treatment reflects physicians' adherence to the guidelines.

SUs such as gliclazide are classified as the second most frequent medication used in patients with T2DM. When BIGUs are contraindicated for instance in patients with renal impairment or with advanced heart failure, SUs are initiated. Our finding here is also consistent with the current guidelines. ${ }^{6}$

In our study, we observed a steady decline in the use of BIGUs during follow-up, which may be explained, at least partly, by launching the new generation of glucose-lowering medications. For patients on BIGUs or SUs who do not achieve glycemic targets, GLP-1 receptor agonists and SGLT2 inhibitors are suggested. ${ }^{16}$ Both medications have been shown effective with minimal risk of hypoglycemia. ${ }^{16}$ In our study, despite the low prevalence rates of GLP-1 receptor agonists and SGLT2 inhibitors, there was an increasing trend over the study period.

It has been reported that compared with women, European men are diagnosed with T2DM at an earlier age. ${ }^{17}$ Diversities in factors such as lifestyle, environmental and genetic factors impact significant differences between men and women in clinical presentation, diabetes progression and unfavorable diabetes-associated complications. ${ }^{18}$ Conventionally, in patients with T2DM, choice of medication treatment, monotherapy, combination therapy or add-on insulin therapy, reflects a balance between several different factors such as efficacy to achieve glycemic control, contraindication due to adverse drug reactions, risk of hypoglycemia, patient preference, the effects on body weight and cost. Although changes in treatment patterns of glucose-lowering medications over time might be influenced by these factors, we consider it good practice that physicians in the Netherlands mostly follow the clinical guidelines.

Our study shows that many treatment paths for treating T2DM exist. Patients may move back and forth through this path or may take a treatment path that is not in line with the standards. Medication changes may be due to the progression of the disease, however, may also be caused by the generic approach to treating T2DM as suggested in the guidelines may work for most, but not all patients. Research that addresses phenotypes, personal and environmental factors in patients may help to target the right treatment to the right patient in an early stage. Studies using novel technologies in the field of 'omics or other big data approaches may provide physicians with new means to diagnose and to treat patients with diabetes effectively. There have been promising results identifying metabolomic biomarkers to enhance personalized treatment in T2DM. ${ }^{19}$

The main strength of this study is that we used the NControl database, a large population-based dataset which provides accurate data on medications dispensing. We included 73819 adults aged $\geq 45$ years who were newly started on oral glucose-lowering medications; therefore, there was little chance of misclassified type 1 diabetes. We developed a technique that allows us to mine the most frequent patterns. The strength of using this technique is that we know and can describe exactly which steps were taken, which may not be as easy when using 'black box' algorithms provided by in-market (open source) software packages. However, there are some limitations in our study that should be acknowledged. Our analysis was performed on pharmacy-based data. Not all patients have an equal follow-up period. Patients that started using T2DM medication in the later years of our study period, have a shorter follow-up period than patients that entered the study in the earlier years, and this may influence some of the results, especially for calculations related to average number of days on treatment or before switch. We know which prescriptions have been filled, but we cannot know with certainty which medications have been taken. Also, some patients may have filled part of their prescriptions in pharmacies outside our NControl universe. However, we do know from other research that patients in the Netherlands are registered with a single community pharmacy, and that records with regard to prescription drugs are virtually complete. ${ }^{20}$ Our database contains no detailed clinical information. There is a possibility that some patients with type 1 diabetes may have been misclassified as patients with type 2 diabetes. Also, if was not possible for us to distinguish patients that may 
suffer from Latent Autoimmune Diabetes in Adults (LADA), which occurs among $9.7 \%$ of patients with adult-onset diabetes, as reported in Action LADA. ${ }^{21}$ Metformin is prescribed mainly for the treatment of T2DM, but may also be prescribed for patients with obesity and pre-diabetes in women of reproductive age, mostly below the age of 45 years. ${ }^{22}{ }^{23}$ On the other hand, since we used pharmacy prescription data, we were not able to assess factors associated with switching; merely age and gender were available. Identifying factors associated with switching would help guide clinicians toward a medication treatment choice and could also help patients to improve their response to treatment. We were able to follow eligible patients with T2DM during a period of 6 years. It is to be expected that due to the progressive nature of the disease and the trend reported in this study, the percentage of patients using insulin at the end of follow-up would have been greater if we would be able to extend this period to longer follow-up. ${ }^{24} 25$

In summary, our study showed different treatment steps for patients initiating oral glucose-lowering medications in the Netherlands. The apparent complex patient journey in treatment choice is mainly consistent with the current clinical guidelines. Our study suggests that the sequential pattern mining can give a clear overview of the most frequent steps in the treatment journey of patients diagnosed with T2DM, that would otherwise be too complex to describe.

\section{Ethical approval}

Data protection is a central issue for research ethics and a fundamental human right. ${ }^{26}$ Use of prescription data in the database of NControl for research purposes is legally permissible. Patient data in the database are pseudonymized. It is impossible for researchers that work with the NControl database to re-identify any natural persons. NControl adheres to data protection and privacy regulations, as established in among others the Personal Data Protection Act in The Netherlands as well as the Netherlands Norm (NEN) 7510 standard on information protection in healthcare, which is derived from International Organisation for Standardization norm 27001 and 27002

\section{Author affiliations}

'Department of Respiratory Disease, Academic Medical Center, Amsterdam, The Netherlands

${ }^{2}$ Department of Internal Medicine, Erasmus MC, Rotterdam, Zuid-Holland, The Netherlands

${ }^{3}$ Department of Epidemiology, Erasmus University, Rotterdam, Zuid-Holland, The Netherlands

Contributors $\mathrm{JMvdH}$ wrote the manuscript, designed the study and performed the analysis. FA co-wrote the manuscript and designed the study. NF co-wrote the manuscript. MvH and A-HM-vdZ gave input on the manuscript. All authors discussed the results and approved the submitted manuscript. JMvdH is the guarantor of this work and, as such, had full access to all the data in the study and takes responsibility for the integrity of the data and the accuracy of the data analysis.
Funding The authors have not declared a specific grant for this research from any funding agency in the public, commercial or not-for-profit sectors.

Competing interests None declared.

Patient consent for publication Not required.

Provenance and peer review Not commissioned; externally peer reviewed.

Data availability statement Data may be obtained from a third party and are not publicly available.

Open access This is an open access article distributed in accordance with the Creative Commons Attribution Non Commercial (CC BY-NC 4.0) license, which permits others to distribute, remix, adapt, build upon this work non-commercially, and license their derivative works on different terms, provided the original work is properly cited, appropriate credit is given, any changes made indicated, and the use is non-commercial. See: http://creativecommons.org/licenses/by-nc/4.0/.

\section{ORCID iDs}

Jan Maurik van den Heuvel http://orcid.org/0000-0003-2775-7276

Mandy van Hoek http://orcid.org/0000-0002-2957-5436

\section{REFERENCES}

1 Whiting DR, Guariguata L, Weil C, et al. IDF diabetes atlas: global estimates of the prevalence of diabetes for 2011 and 2030. Diabetes Res Clin Pract 2011;94:311-21.

2 Foundation ID. IDF diabetes atlas 2017. 8th edn, 2017.

3 Kleefstra N, Landman GWD, Van Hateren KJJ, et al. Dutch diabetes prevalence estimates (DUDE-1). J Diabetes 2016;8:863-5.

4 Bolen S, Feldman L, Vassy J, et al. Systematic review: comparative effectiveness and safety of oral medications for type 2 diabetes mellitus. Ann Intern Med 2007;147:386-99.

5 Rutten GEHM DGW, Nijpels G, Houweling ST, et al. NHGStandaard diabetes mellitus type 2 (derde herziening). Huisarts Wet 2013:56:512-25.

6 Davies MJ, D'Alessio DA, Fradkin J, et al. Management of hyperglycaemia in type 2 diabetes, 2018. A consensus report by the American diabetes association (ADA) and the European association for the study of diabetes (EASD). Diabetologia 2018;61:2461-98.

7 American Diabetes Association. 8. Pharmacologic Approaches to Glycemic Treatment: Standards of Medical Care in Diabetes-2018. Diabetes Care 2018;41:S73-85.

8 van den Heuvel JM, Hövels AM, Büller HR, et al. Noacs replace VKA as preferred oral anticoagulant among new patients: a drug utilization study in 560 pharmacies in the Netherlands. Thromb J 2018;16:7.

9 Garritsen FM, van den Heuvel JM, Bruijnzeel-Koomen CAFM, et al. Use of oral immunosuppressive drugs in the treatment of atopic dermatitis in the Netherlands. J Eur Acad Dermatol Venereol 2018;32:1336-42.

10 ATC/DDD index 2019: who collaborating centre for drug statistics methodology, 2018. Available: http://www.whocc.no/atc_ddd_index [Accessed 23 Apr 2019].

11 Alva ML, Hoerger TJ, Zhang P, et al. Identifying risk for type 2 diabetes in different age cohorts: does one size fit all? BMJ Open Diabetes Res Care 2017;5:e000447.

12 American Diabetes Association. Standards of medical care in diabetes--2009. Diabetes Care 2009;32 Suppl 1:S13-61.

13 UKPDS Group. Effect of intensive blood-glucose control with metformin on complications in overweight patients with type 2 diabetes (UKPDS 34). The Lancet 1998;352:854-65.

14 Sharma M, Nazareth I, Petersen I. Trends in incidence, prevalence and prescribing in type 2 diabetes mellitus between 2000 and 2013 in primary care: a retrospective cohort study. BMJ Open 2016;6:e010210.

15 Berkowitz SA, Krumme AA, Avorn J, et al. Initial choice of oral glucose-lowering medication for diabetes mellitus: a patientcentered comparative effectiveness study. JAMA Intern Med 2014;174:1955-62.

16 Gurgle HE, White K, McAdam-Marx C. Sglt2 inhibitors or GLP1 receptor agonists as second-line therapy in type 2 diabetes: patient selection and perspectives. Vasc Health Risk Manag 2016:12:239-49.

17 Logue J, Walker JJ, Colhoun HM, et al. Do men develop type 2 diabetes at lower body mass indices than women? Diabetologia 2011:54:3003-6.

18 van Ommen B, Wopereis S, van Empelen P, et al. From diabetes care to diabetes Cure-The integration of systems biology, eHealth, and behavioral change. Front Endocrinol 2017;8:381. 
19 den Ouden H, Pellis L, Rutten GEHM, et al. Metabolomic biomarkers for personalised glucose lowering drugs treatment in type 2 diabetes. Metabolomics 2016;12.

20 Buurma H, Bouvy ML, De Smet PAGM, et al. Prevalence and determinants of pharmacy Shopping behaviour. J Clin Pharm Ther 2008;33:17-23.

21 Hawa MI, Kolb H, Schloot N, et al. Adult-onset autoimmune diabetes in Europe is prevalent with a broad clinical phenotype: action LADA 7. Diabetes Care 2013;36:908-13.

22 Johnson NP. Metformin use in women with polycystic ovary syndrome. Ann Transl Med 2014;2.
23 Zhou J, Massey S, Story D, et al. Metformin: an old drug with new applications. Int J Mol Sci 2018;19:2863.

24 Rascati KL, Richards KM, Lopez D, et al. Progression to insulin for patients with diabetes mellitus using the Texas Medicaid database. Clin Ther 2011;33:2016-20.

25 Turner RC, Cull CA, Frighi V, et al. Glycemic control with diet, sulfonylurea, metformin, or insulin in patients with type 2 diabetes mellitus: progressive requirement for multiple therapies (UKPDS 49). UK prospective diabetes study (UKPDS) group. JAMA 1999;281:2005-12.

26 European Commission DG Research and Innovation. Ethics and data protection, 2018. 